\title{
A study of feto-maternal outcome of jaundice in pregnancy
}

\author{
Jyothi G. S., Anannya Chakraborty*, Asha Swarup
}

Department of Obstetrics and Gynecology, Ramaiah Medical College, Bengaluru, Karnataka, India

Received: 26 May 2018

Accepted: 30 May 2018

\section{*Correspondence:}

Dr. Anannya Chakraborty,

E-mail: anannya.doc305@gmail.com

Copyright: (c) the author(s), publisher and licensee Medip Academy. This is an open-access article distributed under the terms of the Creative Commons Attribution Non-Commercial License, which permits unrestricted non-commercial use, distribution, and reproduction in any medium, provided the original work is properly cited.

\section{ABSTRACT}

Background: Jaundice in pregnancy complicates 3-5\% of cases and carries a grave prognosis. The purpose of the study was to assess the epidemiology, magnitude, causes and the maternal and fetal outcome of pregnancies complicated by jaundice.

Methods: The maternal and fetal outcomes of 101 cases of jaundice in pregnancy were reviewed retrospectively from July 2013-June 2016.

Results: The incidence of jaundice in pregnancy was $2.32 \%$. Primigravidas constituted $46.53 \%$. Women aged 20-30 years constituted $86.13 \%$. Unbooked cases included $60.39 \%$. Serum bilirubin was $>10 \mathrm{mg} / \mathrm{dl}$ at admission in $1.98 \%$. Out of the 101 women, 4 remained undelivered. Labor was spontaneous in $53.52 \%$, vaginal delivery in $55.67 \%$. However, $38.63 \%$ newborns required NICU care. Perinatal mortality was $8.91 \%$ (3.96\% stillbirths and $4.95 \%$ early neonatal deaths. The causes for jaundice were viral hepatitis $(30.69 \%)$, HELLP syndrome $(30.69 \%)$, intrahepatic cholestasis $(15.84 \%)$, acute fatty liver of pregnancy $(13.86 \%)$ and the rest in combination constituted $8.91 \%$. Maternal mortality was 3 in 101. The various maternal complications were DIC (44.55\%), septicemia (10.89\%), ARDS $(7.92 \%)$, acute renal failure $(8.91 \%)$ and MODS $(3.96 \%)$. ICU was needed in $14.85 \%$ of mothers and blood component therapy in $70.29 \%$ cases. All deaths were within 3 weeks of admission.

Conclusions: This study emphasizes the need for essential antenatal care at domiciliary and peripheral levels. Early detection and treatment can prevent most of the complications.

Keywords: Bilirubin, DIC, Maternal mortality, Sepsis

\section{INTRODUCTION}

Jaundice is defined as the yellowish discoloration of skin, sclera and mucous membrane resulting from raised serum bilirubin concentration, that is clinically visible when bilirubin level exceeds $3 \mathrm{mg} \%$, the normal level being $0.2-0.8 \mathrm{mg} \%{ }^{1}{ }^{1}$ Liver is one of the organs affected during pregnancy due to hormonal and metabolic changes. Metabolic, synthetic and excretory functions of the liver are affected by the increased levels of estrogen and progesterone in pregnancy. A genetic susceptibility to the cholestatic effect of reproductive hormones and their metabolites may impair the bile secretory function in susceptible women. For example, mutations in ABCB11 gene (ATP Binding Cassette subfamily B) leads to enhanced susceptibility to intrahepatic cholestasis of pregnancy and the lack of ABCB4 gene product results in defective functioning of the phospholipid export pump and impaired biliary secretion of phosphatidylcholine. ${ }^{2}$ The liver receives around $25 \%-35 \%$ of the cardiac output which is not changed during normal pregnancy. Pregnancy is a mild cholestatic condition. Serum biochemical tests rise to 2 to 4 folds during the third trimester. $^{3}$

Normally there is a slight rise in the ALP levels while AST and ALT values remain relatively unchanged. 
Hepatic dysfunction complicates around 3-5\% of pregnancies. The causes may be classified as

- Peculiar to pregnancy - AFLP, Cholestasis of pregnancy and jaundice complicating toxemia of pregnancy,

- Concurrent with pregnancy - Infections (Viral hepatitis), Gallstones, Drugs

- Chronic pre-existing hepatic illness. ${ }^{4}$

The occurrence of hepatobiliary disease with or without jaundice during pregnancy provides both the hepatologist and obstetrician with a diagnostic challenge. Advances in understanding and management of liver disorders unique to pregnancy and hepatobiliary disease in general have resulted in a significant improvement in the outcome for both the mother as well as the fetus. Vaginal delivery should be attempted whenever possible due to increased risk of haemorrhage..$^{5}$ Reasons for high maternal mortality in India include prevalence of anemia, poor nutrition, delay in seeking medical advice and delayed referral. Among the varied causes of jaundice in pregnancy, Hepatitis E is a deadly fetomaternal disease having a feco-oral route of transmission and hence the disease transmission can be decreased by ensuring improved sanitation and providing clean drinking water for pregnant women. ${ }^{6}$

Presenting features of liver disease in pregnancy are nonspecific. Presence of jaundice may lead to intense contractions which shorten the labour duration and increase threat to the fetus. Early diagnosis and treatment is required and hence the need for the study. This study was conducted to study the epidemiology, magnitude and causes of jaundice in pregnancy and to assess the maternal and fetal outcome in pregnancies complicated by jaundice.

\section{METHODS}

The study was conducted in the Department of Obstetrics and Gynecology of Ramaiah Medical College and Teaching Hospital, Bengaluru. It was a retrospective study conducted on 101 antenatal patients with jaundice, who got admitted to Ramaiah Hospital during the period July 2013 to June 2016.

\section{Inclusion criteria}

All pregnant women with singleton pregnancies with spontaneous conception having recent onset of jaundice who got admitted during the aforesaid period Preeclampsia was taken as blood pressure $\geq 140 / 90$ $\mathrm{mmHg}$ or more on two occasions at least 6 hours apart with proteinuria as per international society for the study of hypertension in pregnancy.

\section{Exclusion criteria}

- Multiple pregnancy
- Pregnancies following Artificial Reproductive Techniques

- Alcoholism

- Chronic liver diseases

- Congenital diseases of the hepatobiliary system

- Hemolytic anemis

- Cardiac or Renal diseases.

All the patients were assessed thoroughly by history and physical examination and relevant investigations like Platelet, liver enzymes and Bilirubin were analysed.

History of the presenting illness included symptoms, onset, duration and progression.

Physical examination was carried out with special attention to level of consciousness, built and nutrition, presence of pallor, icterus, edema, lymphadenopathy and vital signs. Also, abdominal examination was done to look for hepatosplenomegaly, abdominal mass, tenderness and ascites. This was followed by detailed obstetrical examination

Maternal and fetal outcomes were statistically analysed. Maternal outcomes included mode of onset of labour and delivery, admission to delivery interval, ICU admission, component therapy, complications and condition at discharge. Fetal outcomes included neonatal mortality/morbidity, NICU admission and condition at discharge.

\section{Statistical analysis}

The demographic variables like age, parity, booking status and socio-economic status were analyzed and presented as frequency and \%age. The comparative statistics of the blood variables were summarized in terms of median with interquartile range since the data was not normally distributed. The maternal and fetal/neonatal outcome was compared using odds ratio-confidence interval calculator. The statistical significance of the variables was calculated using McNemars test and $\mathrm{p}<0.001$ was considered statistically significant.

\section{RESULTS}

Total number of deliveries in the study period was 4350 , out of which, number of cases with jaundice was 101 , hence the incidence of jaundice in pregnancy in our study was $2.32 \%$.

Table 1 depicts the incidence of the demographic variables that includes $2.97 \%$ cases $<20$ years, $86.13 \%$ cases $20-30$ years and $10.89 \%$ cases $>30$ years age group. $60.39 \%$ cases were unbooked, and $46.53 \%$ cases were primigravida. Majority of cases $(62.37 \%)$ belonged to urban areas. Socio-economic status calculated by Modified Kuppuswamy Index showed almost equivalent distribution in all the classes. 
Table 1: Comparative analysis of the demographic variables.

\begin{tabular}{|l|l|}
\hline Variables & Incidence (\%) \\
\hline Age & \\
\hline$<20$ years & $2.97 \%$ \\
\hline $20-30$ years & $86.13 \%$ \\
\hline$>30$ years & $10.89 \%$ \\
\hline Booking status & \\
\hline Booked & $39.60 \%$ \\
\hline Unbooked & $60.39 \%$ \\
\hline Parity & \\
\hline Primi & $46.53 \%$ \\
\hline Multi & $53.46 \%$ \\
\hline Area & \\
\hline Rural & $37.62 \%$ \\
\hline Urban & $62.37 \%$ \\
\hline Socio-economic status & $32.67 \%$ \\
\hline lower class & $31.68 \%$ \\
\hline lower- middle class & $35.64 \%$ \\
\hline Upper middle and upper class & \\
\hline
\end{tabular}

Table 2 illustrates the alterations in the blood variables. Bilirubin and LDH levels were significantly elevated in these.

Table 2: Comparative analysis of blood variables.

\begin{tabular}{|llll|}
\hline Variables & Median (IQR) & $\begin{array}{l}\text { Reference } \\
\text { value }\end{array}$ & $\begin{array}{l}\mathrm{p} \text { - } \\
\text { value }\end{array}$ \\
\hline Platelet count & $1.4(0.9-1.8)$ & 1.5 & 0.419 \\
\hline Bilirubin & $1.6(1.4-2.4)$ & 0.3 & $<0.001$ \\
\hline AST & $45(42-58)$ & 50 & 0.623 \\
\hline ALT & $90(67-103)$ & 80 & 0.213 \\
\hline LDH & $201(154-280)$ & 150 & $<0.001$ \\
\hline
\end{tabular}

Other observations included were thrombocytopenia and elevated liver enzymes, but the change was not statistically significant.

Table 3 analyses the maternal outcome. Vaginal delivery was successful in $53.52 \%$ cases, $44.47 \%$ cases underwent LSCS, however $3.96 \%$ patients went against medical advice undelivered. $96.9 \%$ cases delivered within 10 days of admission.

Component therapy was needed in $70.29 \%$ cases, but only $14.85 \%$ patients required ICU care, the rest were aptly managed in the high dependency unit. $85.14 \%$ patients were discharged in a stable condition while $1.98 \%$ cases were transferred to other department for further management following delivery.

Table 4 analyses the association of maternal complications with jaundice. DIC was found to have the maximum association of $44.55 \%$ requiring component therapy in all the cases, mandating ICU care in some of them. Also, it depicts the causes of maternal death in 3 out of 101 cases.
DIC, AKI and Sepsis (66.66\%) were the leading causes of maternal death followed by ARDS and MODS $(33.33 \%)$ with considerable overlap among them.

Table 3: Maternal outcome analysis.

\begin{tabular}{|llll|}
\hline Variables & Incidence & OR & $95 \%$ CI \\
\hline Labour onset & & & \\
\hline spontaneous & $53.52 \%$ & - & - \\
\hline induced & $46.47 \%$ & - & - \\
\hline Mode of delivery & & & \\
\hline VD & $55.67 \%$ & 4.86 & $4.01-5.32$ \\
\hline LSCS & $44.32 \%$ & 3.66 & $3.10-4.23$ \\
\hline Rest & $3.96 \%$ & - & - \\
\hline Admission-delivery interval & & \\
\hline$<10$ days & $96.90 \%$ & 16.58 & $14.99-18.03$ \\
\hline$>10$ days & $2.06 \%$ & 2.67 & $2.20-3.01$ \\
\hline rest & $3.96 \%$ & - & - \\
\hline Component therapy & & \\
\hline Yes & $70.29 \%$ & 5.88 & $4.98-6.40$ \\
\hline No & $29.70 \%$ & 1.18 & $0.67-2.33$ \\
\hline ICU admission & & & \\
\hline Yes & $14.85 \%$ & 1.33 & $1.04-1.78$ \\
\hline No & $85.14 \%$ & 6.77 & $6.34-6.95$ \\
\hline $\begin{array}{l}\text { LAMA } \\
\text { Improved and }\end{array}$ & $8.91 \%$ & 1.59 & $1.03-1.93$ \\
\hline $\begin{array}{l}\text { discharged } \\
\text { another }\end{array}$ & $85.14 \%$ & 4.90 & $4.54-5.21$ \\
\hline department & $1.98 \%$ & 0.05 & $0.01-0.73$ \\
\hline
\end{tabular}

Table 4: Analysis of associated complications.

\begin{tabular}{|llll|}
\hline Complication & Incidence & OR & $95 \%$ CI \\
\hline DIC & $44.55 \%$ & 3.88 & $2.93-4.05$ \\
\hline Sepsis & $10.89 \%$ & 1.88 & $1.29-2.23$ \\
\hline ARDS & $7.92 \%$ & 1.67 & $1.30-1.99$ \\
\hline ARF & $8.91 \%$ & 1.73 & $1.56-1.90$ \\
\hline MODS & $3.96 \%$ & 0.94 & $0.52-1.27$ \\
\hline Death & $2.97 \%$ & 0.73 & $0.31-0.92$ \\
\hline Cause of death & & & \\
\hline DIC & $66.66 \%$ & 2.89 & $2.01-3.31$ \\
\hline AKI & $66.66 \%$ & 2.89 & $2.01-3.31$ \\
\hline ARDS & $33.33 \%$ & 1.15 & $0.92-1.58$ \\
\hline Sepsis & $66.66 \%$ & 2.89 & $2.01-3.31$ \\
\hline MODS & $33.33 \%$ & 1.15 & $0.92-1.58$ \\
\hline
\end{tabular}

Table 5 describes the neonatal outcome - live born (87.12\%), still birth (3.96\%) and neonatal death (4.95\%), and the $3.96 \%$ cases remained undelivered.

Commonest cause of neonatal death was birth asphyxia $(60 \%)$. Babies were handed over to mother at birth in $68.18 \%$ cases, within 2 weeks in $13.63 \%$ cases, within 15-30 days in $5.68 \%$ cases, $30-50$ days in $9.09 \%$ cases and $>50$ days in $2.27 \%$ cases. $1.13 \%$ babies were discharged against medical advice and were lost to follow-up. 
Table 5: Neonatal outcome.

\begin{tabular}{|llll|}
\hline Outcome & Incidence & OR & $95 \%$ CI \\
\hline Born alive & $87.12 \%$ & 3.39 & $2.91-3.59$ \\
\hline Still birth & $3.96 \%$ & 0.57 & $0.14-0.73$ \\
\hline Neonatal death & $4.95 \%$ & 0.71 & $0.38-1.00$ \\
\hline Asphyxia & $60 \%$ & 9.63 & $8.01-9.92$ \\
\hline IUGR & $20 \%$ & 3.01 & $2.57-3.39$ \\
\hline LBW & $20 \%$ & 3.01 & $2.57-3.39$ \\
\hline NICU admission & $38.63 \%$ & 2.11 & $1.63-2.45$ \\
\hline Cause of NICU & & & \\
\hline Birth asphyxia & $35.29 \%$ & 0.19 & $0.08-0.23$ \\
\hline IUGR & $35.29 \%$ & 0.19 & $0.08-0.23$ \\
\hline LBW & $29.41 \%$ & 0.05 & $0.01-0.13$ \\
\hline
\end{tabular}

\section{DISCUSSION}

Management of jaundice in pregnancy is a common, albeit challenging, clinical endeavor. A multidisciplinary collaboration is required between obstetrician and gastroenterologist in the management decisions. Diagnosing pregnancy-related causes of abnormal liver function tests is important because immediate intervention and delivery may be needed. Conversely, conditions unrelated to pregnancy might be exacerbated by pregnancy and delivery. ${ }^{7}$

The incidence of jaundice in this study was $2.32 \%$. The incidence is higher compared to US statistics but similar to other Indian studies. This is because of low socioeconomic status, poor sanitation and delayed referrals to tertiary centres. Majority of the patients (more than two thirds) in the study belonged to 20-30 years age group with 3-fold increased risk of jaundice. The disease seemed to be more prevalent in the active reproductive age group. Around two-third of the patients were unbooked. This highlights the need for regular antenatal checkup, especially in high risk cases, to aid early identification of the disease and prompt treatment or referral if needed. No significant difference in parity was noted, hence both primigravidae and multigravidae are at risk and to be carefully attended for any symptoms or signs of liver disease during pregnancy. In this study, risk is 9 -fold in $3^{\text {rd }}$ trimester compared to $2^{\text {nd }}$ trimester. This may correlate with the growing demands of the fetus and the consequent burden on the maternal metabolism to meet the requirements as the pregnancy advances. Hence extra precaution to be taken as the fetus grows, jeopardizing the maternal status. If the fetal maturity is documented and with a worsening maternal condition, termination of pregnancy to be planned with a hope to have a considerably good materno-fetal outcome. Socioeconomic status did not reveal significant impact on the incidence of jaundice (Table 1). $60.30 \%$ cases were referred $1 / 3^{\text {rd }}$ from rural centres and remaining from urban health centres. It is to be emphasized here that if jaundice is detected in pregnancy, maternal complications to be anticipated along with a poor fetal outcome. If the concerned health care centre is not well equipped to handle to poor outcome of the mother and/or the fetus, early referral to higher centre is imperative to achieve the best results. According to a study conducted by Ambreen et al,57.7\% were unbooked and $42.2 \%$ were booked. ${ }^{4}$ $71.02 \%$ patients were between $20-30$ years of age and $28.98 \%$ were between $30-40$ years age. According to a study conducted by Acharya et al, overall incidence of $0.4 \%$ jaundice in pregnancy was reported. ${ }^{3}$ The disease was more commonly seen in younger age group. Parity has no exact relation with the disease. This was in concurrence with the findings in our study.

Blood investigations showed significant changes with respect to serum bilirubin that increased by 5 -fold and LDH that increased by $75 \%$ from reference value. However no significant changes were noted in platelet count and liver enzymes, although variations like thrombocytopenia and mild alterations of liver enzymes were noted. (Table 2) This correlated well with the need for component therapy in the patients with altered blood parameters. This explains why jaundice in pregnancy needs management in a tertiary care institute that is well equipped with 24-hour blood bank facility. According to study conducted by Namrata Kumar et al, adverse fetal outcomes were significantly associated with rising serum bilirubin levels of more than $11 \mathrm{mg} / \mathrm{dL}$, serum glutamic oxaloacetic transaminase (SGOT) and serum glutamic pyruvic transaminase (SGPT) of more than $1000 \mathrm{IU} / \mathrm{L}$, and a platelet count of less than $85.000 \mathrm{cells} / \mathrm{mm}$, and this difference was statistically significant. $^{3}$ Maternal outcomes were also significantly poorer in cases of serum bilirubin of more than $14 \mathrm{mg} / \mathrm{dL}$, SGPT more than 1600 , and SGOT more than 1200 and platelets less than 59.000 cells $/ \mathrm{mm}^{3}$

Proportion of patients who had spontaneous and induced labour were similar out of which $55.5 \%$ delivered vaginally, $44.3 \%$ by caesarean section and $3.9 \%$ remained undelivered till discharge. Admission-delivery interval was significantly high within 10 days of admission. Caesarean section was done due to obstetric indications or worsening maternal conditions, however, vaginal delivery is preferred due to fear of increased bleeding tendency in these patients. Pregnancy could not be prolonged much beyond 10 days due to non-response to therapy or worsening of the disease with advancing pregnancy. According to Reddy et al, in $55.6 \%$ cases onset of labour was spontaneous. $88.9 \%$ delivered vaginally. $^{8} 83.3 \%$ of women were discharged in improved condition. Although $75 \%$ of patients required component therapy, only $14 \%$ needed ICU care, the remaining patients were aptly managed in the high dependency unit (HDU). The overall maternal outcome was fairly good with significant improvement at discharge (Table 3). As a good proportion of the patients with jaundice belong to the lower strata of the society, unaffordability of ICU charges may be a cause for the poor outcome. In our study, $8.91 \%$ of the cases were discharged against medical advice due to inability to meet the costs of ICU treatment. On the contrary, $86 \%$ patients were managed in the HDU with successful outcome. 
Hence, establishing an improvised HDU in the tertiary care centres to deal with such cases effectively, avoiding the burden of ICU care has to be borne in mind.

In present study, among the causes of jaundice, maximum association was with hepatitis and HELLP syndrome, but nothing seemed significantly associated. The incidence of each cause was - Hepatitis (30.69\%), HELLP (30.69\%), Cholestasis of pregnancy $(15.84 \%)$, AFLP $(13.86 \%)$ and others $(8.91 \%)$. DIC was the leading complication accounting for half of the cases, followed by sepsis, ARF, ARDS, MODS and death. In the study by Reddy et al, HELLP syndrome, acute fatty liver of pregnancy, intrahepatic cholestasis of pregnancy, viral hepatitis, malaria and sickle cell anemia were the causes of jaundice in this study with HELLP syndrome being the most common cause of jaundice. ${ }^{8}$ Maternal death occurred in 3 out of 101 cases, resulting from DIC, AKI and Sepsis twice more commonly than with ARDS and MODS. (Table 4). Two-thirds of the deaths occurred more than 15 days from admission. Serum bilirubin at death was $>25 \mathrm{mg} / \mathrm{dl}$ in 1 out of 3 deaths. There were no antenatal deaths in this study. All the 3 deaths were reported in the ICU cases while all the patients managed in HDU went home well. This emphasizes the need for further improvement in the critical care in the institute to deal with the severe complications more efficiently. In a study by Reddy et al, maternal mortality was seen in $16.66 \%$ cases, of this 1 case died within 24 hour of delivery, 1 on the $4^{\text {th }}$ postnatal day and 1 on $8^{\text {th }}$ postnatal day. ${ }^{8}$ Cause of death was acute fatty liver of pregnancy with multiorgan failure with disseminated intravascular coagulation (DIC) with shock in 2 cases, HELLP syndrome with DIC with renal failure in 1 case.

Early neonatal death was seen in 6 cases accounting for $4.95 \%$. Neonatal death was 3-fold more due to asphyxia than IUGR and LBW. Asphyxia and IUGR led to similar number of NICU admissions followed by LBW. (Table 5). This emphasizes the role of perinatal asphyxia as a leading cause of poor neonatal outcome. Adequate measures should be taken to avoid perinatal asphyxia in the newborn. This calls for intensive fetal monitoring in the antenatal period with an able group of obstetricians, neonatologists, a skilled team of nursing staff and an amply equipped HDU for fetal monitoring along with maternal care. As per study Kumar et al, 96\% patients presented in third trimester of pregnancy while $4 \%$ pregnancy ended in the second trimester as a missed miscarriage. $84 \%$ babies were born alive, $86 \%$ of which were preterm. ${ }^{6}$ Perinatal mortality was $26 \%$, which was contributed to by intrauterine deaths and early neonatal deaths in $14 \%$ cases each.

The present study reported a maternal death rate of $2.97 \%$ which is quite less compared to other the maternal mortality rates in other similar studies (Table 6). ${ }^{8} \mathrm{~A}$ similar study conducted by Kamalajayaram et al in 1988 reported a maternal mortality rate of $12.4 \%{ }^{9}$ Roychowdhary et al in 1990 reported a maternal death rate of $13.37 \%$, Bera et al in reported $19.9 \%$ maternal mortality in his study on pregnant patients. ${ }^{10,11}$ Sapre at al and Rao et al conducted similar studies and reported maternal deaths of $4.99 \%$ and $15.8 \%$ respectively in their studies. $^{12,13}$ In 2003 and 2005, two more studies conducted, reported maternal mortality rates of $29 \%$ by Trivedi et al and $14.4 \%$ by Tripti $\mathrm{N}$ et al respectively. ${ }^{14,15}$ The higher mortality rates in these studies indicates the poor antenatal care and health care facilities two -three decades ago. Absence of standard tools for diagnosis of the disease, specialized units for maternal and neonatal care as well as lack of awareness among the population in those days, thereby delaying referral and treatment onset all contributed to a higher maternal mortality rate.

Table 6: Comparison with reported maternal deaths due to jaundice.

\begin{tabular}{|lll|}
\hline Authors & Year & $\begin{array}{l}\text { Maternal } \\
\text { mortality }\end{array}$ \\
\hline Kamalajayaram et al & 1988 & $12.4 \%$ \\
\hline Roychowdhary et al & 1990 & $13.37 \%$ \\
\hline Bera et al & 1992 & $19.9 \%$ \\
\hline Sapre et al & 1999 & $4.99 \%$ \\
\hline Rao et al & 2001 & $15.8 \%$ \\
\hline Trivedi et al & 2003 & $29 \%$ \\
\hline Tripti N et al & 2005 & $14.4 \%$ \\
\hline Present study & $2013-2016$ & $2.97 \%$ \\
\hline
\end{tabular}

A recent guideline from the American College of Gastroenterology (ACG) on the evaluation and management of liver disease during pregnancy includes other liver diseases, such as liver masses, biliary tract disease, and viral infections, that can be present during pregnancy.

\section{ACG recommendations}

A pregnant patient with abnormal liver tests should undergo standard work-up as with any non-pregnant individual. ${ }^{16}$ Viral hepatitis is the commonest cause of jaundice in pregnancy. Generating public awareness about the Hepatitis virus, various routes of transmission of the infective hepatitis, improving sanitary conditions, providing health education and knowledge of preventive measures, routine and regular antenatal checkups and viral markers as a part of routine antenatal screening can be useful in reducing the burden of jaundice in pregnancy. ${ }^{17}$ The features of hepatobiliary disease in pregnancy are varied and include jaundice, nausea, vomiting, pruritus, abdominal pain, and altered liver function tests. Specific patterns that occur during pregnancy may lead to easy recognition of the underlying disease. Mild jaundice can be conservatively treated, and recovery is possible. However, moderate to severe jaundice in late trimester have poor effect on health of both mother and fetus. ${ }^{18}$ High maternal mortality in our country is due to poor nutrition, prevalence of anemia, delay in seeking medical advice and delay in referral to the higher centre. Many patients are already in moribund 
condition by the time they are brought to the hospital and often, do not respond to treatment. Jaundice and pregnancy is a deadly combination leading to a very high perinatal as well as maternal morbidity and mortality and requires an early diagnosis and careful management. Some entities have well-defined criteria for diagnosis that also allows classifying the disease according to its severity. Management may be simple for some conditions, and some require termination of pregnancy. In critical conditions, there is ardent need to have expert obstetric and specialists care to help improve the outcomes. $^{19}$

\section{CONCLUSION}

This study emphasizes the need for essential antenatal care at domiciliary and peripheral levels. Early detection and treatment can prevent most of the complications and lead to a better perinatal outcome.

\section{ACKNOWLEDGMENTS}

Authors would like to thank all the staff in the Department of Obstetrics and Gynecology and all the participated mothers and babies for their support during study.

Funding: No funding sources

Conflict of interest: None declared

Ethical approval: Not required

\section{REFERENCES}

1. Choudhary N, Sen S, Varalakshmi K. A prospective study on pregnancy complicated with jaundice with special emphasis on fetomaternal outcome. Int Journal Reprod Contracep Obstet Gynecol. 2017;6(11):5081-8.

2. Feng C, Li WJ, He RH, Sun XW, Wang G, et al. Impacts of different methods of conception on the perinatal outcome of intrahepatic cholestasis of pregnancy in twin pregnancies. Scientific Reports. 2018;8(1):3985.

3. Acharya N, Acharya S, Shukla S, Athvale R. Study of Jaundice in Pregnancy. Global J Med Res. 2014;13(2):e(2013).

4. Ambreen A, Ahmed F, Sheikh A, Ayub MR, Faryad $\mathrm{N}$, Mushtaq S. Jaundice in pregnancy: a clinical study at Fathima memorial system. J South Asian Fed Obstet Gynecol. 2015;77(1): 22-25

5. Houston R, Hayes J, Wildman K, Allerheiligen D. Jaundice and Disseminated Intravascular Coagulopathy in Pregnancy. JABFP. 2017;13(1):7073.
6. Kumar N, Das V, Agarwal A, Pandey A, Agrawal S. Fetomaternal outcomes in pregnant women with hepatitis E infection; still an important fetomaternal killer with an unresolved mystery of increased virulence in pregnancy. Turk J Obstet Gynecol. 2017;14(2):106.

7. Cohen ER, Tram.T. Jaundice and pregnancy: Why going viral is out of style. Dig Dis Sci. 2017;62(2): 294-95.

8. Reddy MG, Prabhakar GC, Sree V. Maternal and fetal outcome in jaundice complicating pregnancy. J NTR Univ Health Sci. 2014;3(4):231-3.

9. Kamalajayaram V, Rama Devi A. A study of maternal mortality in jaundice. J Obstet Gynecol India 1988;38:439-41.

10. Roychowdhary G, Ganju V, Dewan R. Review of maternal mortality over nine year period at Safdarjang Hospital. New Delhi. J Obstet Gynecol India. 1990;40:84-8.

11. Bera SK, Sen Gupta A. A 12 years study of maternal deaths in Eden hospital. J Obstet Gynecol India. 1992;42:182-8.

12. Sapre S, Joshi V. Changing trends of maternal mortality rate in last 26 years at an apex level teaching hospital in Northern Madhya Pradesh. J Obstet Gynecol India. 1999;49:53-6.

13. Rao KB, Rudra G. Hepatitis in Pregnancy. In: Krishna U, Tank DK, Daftary S. (eds). Pregnancy at risk; Current Concepts 4 th edn. Delhi. Japee publication; 2001:128-31.

14. Trivedi SS, Goyal U, Gupta U. A study of maternal mortality due to viral hepatitis. J Obstet Gynecol India. 2003;53:551-3.

15. Nagaria T, Agrawal S. Fetomaternal outcome in jaundice during pregnancy. J Obstet Gynecol India 2005;55:424-7.

16. Zetterman RK. Updated advice on managing liver disease during pregnancy. Medscape. 2015.

17. Krishnamoorthy J, Murugesan A. Jaundice during pregnancy: maternal and fetal outcome. Int J Reprod Contracept Obstet Gynecol. 2017;5(8):2541-5.

18. Joshi R, Dalal N. Fetomaternal outcome and raised bilirubin level in pregnancy. Int $\mathbf{J}$ Reprod Contracep Obstet Gynecol. 2017;6(2):710-3.

19. Ahmed KT, Almashhrawi AA, Rahman RN, Hammoud GM, Ibdah JA. Liver diseases in pregnancy: diseases unique to pregnancy. World J Gastroenterol. 2013;19(43):7639.

Cite this article as: Jyothi GS, Chakraborty A, Swarup A. A study of feto-maternal outcome of jaundice in pregnancy. Int J Reprod Contracept Obstet Gynecol 2018;7:2628-33. 